\title{
Individual Practices to Increase the Graduation Rate of African American Students at Predominantly White Colleges and Universities
}

\author{
William T. Hoston, Shanna L. Graves, and Marche Fleming-Randle
}

African American students face a number of institutional barriers when admitted to Predominantly White Colleges and Universities (PWCUs). Many of the obstacles they encounter are related to historical racism, stereotypes, and prejudices embedded in the culture of these institutions. Even though the enrollment of African American students at these institutions continues to increase, their completion rate remains low. While past studies have examined institutional strategies to increase the African American graduation rate, they have failed to provide recommendations on the individual level for these students to practice. This article explores an important question: What individual strategies are important for African American students to practice in an effort to graduate from PWCUs? Using semi-structured interviews of tenured African American faculty at PWCU's, ten recommendations were proposed to practice.

In a 2001 report by the Department of Educational Statistics, Provasnik and Shafer (2004) found that $87.1 \%$ of African American undergraduates attended PWCUs. In a later study, Cross (2007) found that the percentage of African American undergraduate students attending PWCUs remains at a steady average, slightly above $85 \%$. Despite the high percentage of African Americans enrolled at these institutions, only $43 \%$ account for undergraduate degrees conferred (Cross, 2007).

Research has shown that colleges and universities have created a myriad of retention strategies for students of all races as a means to increase the overall graduation rate (Bennett \& Okinaka, 1990; Braxton, Hirschy, \& McClendon, 2004; Johnson et al., 2005). According to Rodgers and Summers (2008), PWCUs have made efforts to increase the graduation rate of African American students

William T. Hoston (hoston@uhcl.edu) is a Convener for the Political Science program and an Assistant Professor in the School of Human Sciences and Humanities at University of Houston - Clear Lake.

Shanna L. Graves (gravess@uhcl.edu) is an Assistant Professor in the School of Education at the University of Houston - Clear Lake

Marche Fleming-Randle (marche.fleming-randle@wichita.edu) is an Assistant Dean for the Fairmount College of Liberal Arts and Sciences at Wichita State University 
by implementing retention strategies such as tutorial programs, promoting faculty-student partnership programs, and overseeing the effectiveness of multicultural organizations to offset the racial climate that is often favorable to White students. In a similar study, Love (2008) argued that determining institutional initiatives for PWCUs is paramount in retaining African American students. The author states, "The development and successful implementation of diversity programs is critical for student success" (p. 121).

The low graduation rate of African Americans at PWCUs continues to highlight the need to address this problem. This article provides recommendations for these students by exploring the question: What individual strategies are important for African American students to practice in an effort to graduate from PWCUs? We consulted tenured African American professors at PWCUs to provide individual strategies to deal with the social and academic adjustments for African American students entering PWCUs.

\section{Barriers to Success}

Researchers have examined many facets of African American students' experiences, from institutional barriers to retention efforts. African American students, compared to their White counterparts, face a myriad of barriers in pursuit of their educational goals. Often times, these barriers negatively affect African American students' perceptions and experiences while enrolled in college and, subsequently, lead them to withdraw from PWCUs. A number of studies have reported overt and covert forms of racism, stereotypes, feelings of alienation and loneliness, and a constant need to prove one's worthiness as some of the experiences African American students face at PWCUs (Davis et al., 2004; Jones, Castellanos, \& Cole, 2002; Love, 2008; Rodgers \& Summers, 2008; Sedlacek, 1999; Solorzano, Ceja, \& Yosso, 2000).

In a qualitative study examining ethnic minority students' college experiences at a predominately White institution, Jones et al. (2002) found that these students believed their race and ethnicity played a significant role in their college experience. The authors reported mixed findings in relation to minority students feeling like they don't belong and facing discrimination. African American students, in particular, felt like outsiders in non-ethnic specific organizations and identified "a non-representation of their values" (p. 30). Students from all of the underrepresented groups (i.e., African American, Native American, Asian-Pacific American, and Chicano/Latino) reported a lack of support for diversity.

Jones et al. (2002) also analyzed minority students' perspectives about the effectiveness of cross-cultural centers at their institutions. They found that the existence of such centers enhanced the students' on-campus experience and provided a place where minority students could receive support and guidance. According to Sedlacek (1999), "Blacks need a supportive group that can give them advice, counsel, and orientation to sustain them as they confront the larger, often hostile systems they must negotiate" (p. 542). In an earlier article, Allen (1992) argues, as well, that a supportive environment makes a difference in African 
American students' experience on campus. He posed that African American students on Black campuses do better-socially and academically-than their African American peers at PWCUs because they experience more positive "feelings of engagement, connection, acceptance, and extensive support and encouragement" (p. 39).

Davis et al. (2004) also provided insight into African American students' experiences at a PWCU. In the authors' phenomenological research, 11 African American undergraduate students at a predominately White southern university were asked to describe some of the negative college experiences that stood out to them. Their findings revealed that African American students experienced incidents of unfairness, sabotage, and condescension on the part of their White peers, as well as from their White professors. Consequently, this led to African American students' belief that they needed to prove their academic worth. According to Davis et al. (2004), "Having to prove one's worthiness represents a potentially serious barrier to success for Black students in a predominately White university" (p. 439).

\section{Institutional Strategies}

Much of the research on African American matriculation in PWCUs focuses on retention efforts, such as academic remedial/tutorial programs, college preparation programs, student services, multicultural events and organizations, cultural centers, and faculty-student partnership programs (Kobrak, 1992; Love, 2008; Patton, Morelon, Whitehead, \& Hossler, 2006; Nagda, Gregerman, Jonides, von Hippel, \& Lerner, 1998; Tierney, 1999). These approaches warrant exploration, as they have been implemented by various PWCUs to retain minority students.

Some researchers have argued that early intervention can greatly affect minority students' college experiences. In a study conducted by Tierney (1999), focusing on a college preparation program entitled the Neighborhood Academic Initiative, the author found that early intervention programs prepared adolescent African Americans and Latinos for college. The program, housed on the University of Southern California's campus, prepared low-income minority adolescents in grades 7 through 12 for college by enhancing the students' cultural capital as a means to facilitate their transition to college. According to the author:

Minority students from inner-city neighborhoods can be perceived as requiring embodied and objectified capital, and ultimately institutionalized capital, if they are to gain access to college...the Neighborhood Academic Initiative can be viewed as helping to develop agency among their participating students and families so that the habitus of these groups does not become a deterministic structure that merely reproduces the social order (p. 88).

Tierney concluded that such programs are important to prepare racial and ethnic minority students prior to entering mainstream institutions. These programs offer specific strategies to promote cultural awareness for students entering PWCUs.

The student-faculty relationship, in particular, is critical to minority students' 
college experience, especially for African American students at PWCUs. Previous studies argue that African American student retention efforts cannot be successfully achieved without faculty interaction (Kobrak, 1992; Love, 2008; Nagda et al., 1998). Nagda et al. (1998) explored the faculty-student relationship in their study of the Undergraduate Research Opportunity Program (UROP) at the University of Michigan. The major goal of this program was to "broker intellectual relationships between faculty and first-year and sophomore undergraduates through research partnerships" (p. 58). A primary finding of their study was increased retention rates for the majority of students. When controlling for race, the authors found that African Americans benefitted more than other racial and ethnic groups. The amount of contact African American students had with faculty influenced their rate of retention and academic performance. Nagda et al. contend that the interaction between faculty and African American students contributes to their identification with the institution, thus creating a feeling of belonging.

\section{African American Student Accountability}

Despite the plethora of institutional barriers African American students face, many are able to achieve academic success (Allen, 1992; Davis et al., 2004). Studies have found that African American students are able to overcome historical racism, stereotypes, and prejudices embedded in the culture of these institutions. Can institutional strategies alone attribute to African American students' academic success, or does individual persistence play a more substantial role? According to Allen (1992):

The way a student perceives and responds to events in the college setting will differentiate his or her college experience and shape his or her college outcomes. What he or she does when confronted with difficult subject matter, how he or she handles the uncertainty of new situations, and how adept he or she is in help-seeking behavior will ultimately determine whether a student's college experience is positive or negative (p. 39).

Because the majority of scholarly research on African American academic achievement focuses on institutional strategies to increase retention, we argue that it is imperative to highlight strategies that these students can practice to increase their graduation rates at PWCUs.

\section{Individual Practices for African American Students}

Semi-structured interviews helped to explore attitudes and beliefs about the low graduation rate of African American students in this study. According to Berg (1998), "This type of interview involves the implementation of a number of predetermined questions...in a systematic and consistent order, but the interviewers are allowed freedom to digress; that is, the interviewers are permitted to probe far beyond the answers" (p. 61). 
A convenience sample of 16 tenured African American faculty members from PWCUs were interviewed. The professors were faculty members at various major colleges and universities in the Southeast region of the United States. The faculty members were housed in the departments of Sociology, Psychology, Curriculum and Instruction, Business, Engineering, and Chemistry. Each respondent was asked his or her thoughts on the low graduation rate of African American students and what strategies they believe are important for these students to employ to increase their ability to graduate? Depending on the responses from these individuals, probing questions were asked for clarity and further discussion on the topic. A number of themes emerged which have been ranked and provided as ten best practices to increase the graduation rate for African-African students at PWCUs.

\section{Have a Positive Attitude about Learning.}

African American students should approach each class, even those which are not in their major, with a positive attitude. A student's attitude toward learning often dictates how well he or she will perform in class and how much information he or she will retain. A serious misconception of many students is that some classes are not essential to their learning process. Students should look to engage in the lecture, be active listeners, take thorough notes, participate in discussion, and meet with the instructor after class if clarification is needed. African American students must be committed to learning while in class, internalize lecture content, and be immersed in the subject matter.

\section{Don't Be Late; Sit in Front of the Class; and Pay Attention.}

Students have to recognize the significance of punctuality, presence, and attentiveness. They should approach class like a business meeting, where promptness, attention to detail, and retention of information is central to success. Also, an instructor will notice students who sit in front. Students who sit in back may not be in the best sight line of the instructor. Sitting in front acts as a cue that the student is paying attention and interested in the subject matter. These practices are critical for African American students to gain credibility in the classroom and avoid general stereotypes often associated with them.

\section{Participate in Class Discussions.}

Although the curriculum presented may not at times elicit their interest, it is imperative that they listen to peer interaction and partake in class discussion. One way to move in this direction is to routinely ask the instructor questions for clarification. This will lead to an exchange with the instructor and exhibit the student's interest in the subject matter. It is also useful when the student introduces African American experiences that enlarge the parameters of the discussion. This practice will help to erode any general stereotypes that the instructor and class members may have about African American students' background and academic aptitude. 


\section{Don't Be Afraid to Visit Professors' Offices.}

Instructors enjoy talking to students who take an interest in their courses. Students should visit the instructor's office early in the semester to ensure the instructor knows their names and that they are excited to learn about the subject matter. If students have specific questions related to the course, syllabi, or other course materials, they should not be afraid to ask. Students should be self-initiating in the learning process. Instructors will view this as a sign that African American students value their education.

\section{Be Sure To Obtain an Effective Advisor.}

We identify this practice as essential to increasing the graduation rate. Because academic advising is an ongoing process, students need advisors who will assist in the assignment of classes and provide strong academic mentorship and support. African American students should be able to assess their relationship with the advisor and recognize if they can establish a working relationship that is conducive for academic success. If not, they should request an advisor whom they feel comfortable with as it is important for African American students to align themselves with advisors who understand their educational goals.

\section{Build Strong Networks on Campus.}

African American students at PWCUs should build social networks with students from other ethnic backgrounds. They should get to know and interact with a diverse group of students. Because the percentage of African American students on most PWCUs is relatively small, they tend to alienate themselves from other racial groups and form small cohorts. Building networks with a diverse demographic of students can lead to positive relationships and extended support. This practice should benefit African American students and help to eliminate the feeling of alienation and isolation felt at these institutions.

\section{Get Involved in Student Activities.}

Joining student organizations give African American students the opportunity to have a voice on campus, be an agent of change, understand how the campus-community involvement works, and more importantly, make friends. Also, getting involved in various campus organizations can lead to scholarship opportunities, future jobs, and travel opportunities with the school. The experience demonstrates to future employers and graduate school admission committees that a student is well-rounded, has leadership ability, and can manage his or her time. African American students can also get involved in national honor societies. Involvement will enrich their university experience and enhance their social skills.

\section{Dress for Success.}

It is critical for African American students to make a good first impression on administrators, faculty members, staff, and peers by being dressed appropriately when they participate in campus functions and attend class. Students should 
understand that their instructors might interpret their dress differently than how they meant to present themselves. They should keep this in mind and be deliberate about their presentation. African American students do not want to be stereotyped as "thuggish" or "ghetto."

\section{Don't Be Afraid to Show Intelligence.}

African Americans should not be embarrassed to show that they are good students. Sometimes when students feel alienated from class discussion, or when the class lecture is not engaging, they will not be active in the learning process. This can be perceived as not paying attention. Being engaged in the lecture and subject matter shows the instructor that the student has a genuine interest in the course and helps remove preconceived notions about the student's educational aptitude. African American students should not hide their intelligence as an ability to excel can lead to opportunities to work with faculty on research, present at research conferences, and secure scholarship funds.

\section{Work Hard To Finish College.}

Students must realize that college is more difficult than high school, and that there is no substitute for hard work. It is imperative to put forth the necessary time and effort to study, be organized, and get good grades. Also, students must learn how to make sacrifices. College lasts for a short; while students are in college, they should be committed to finishing. African American students must understand the importance of academic achievement which cannot be gained without hard work.

\section{Conclusion}

The above ten practices are not exhaustive, but they represent key individual strategies to help increase the number of African American students attaining a college degree from PWCUs. Students who employ these practices should experience a higher level of academic success in the classroom and more social inclusiveness on campus. These practices should be used as major guiding principles against the stereotypes, and prejudices that exist at these institutions. These practices add credibility to the research on African American students at Predominantly White Colleges and Universities.

This article details social and academic strategies for African American students on the individual level, whereas past articles have examined the declining African American graduation rate only focusing on institutional strategies. This is a new angle to investigate this problem. To date, no study in the field has done so. In addition, these newly developed strategies are provided from tenured African American professors working at PWCUs who have extensive knowledge of the institutional barriers facing African American students. These professors understand the historical racism, stereotypes, and prejudices embedded in the culture of these institutions, and their proposed recommendations are suited to increase the graduation rate of African American students at PWCUs. 
Allen, W. R. (1992). The color of success: African American college student outcomes at predominately White and historically Black public colleges and universities. Harvard Educational Review, 62(1), 26-44.

Bennett, C., \& Okinaka, A. M. (1990). Factors related to persistence among Asian, Black, Hispanic, and White undergraduates at a predominately White university. The Urban Review, 22, 33-60.

Berg, B. L. (1998). Qualitative research methods for the social sciences (3rd ed.). Boston: Allyn and Bacon.

Braxton, J. M., Hirschy, A. S., \& McClendon, S. A. (2004). Understanding and reducing college student departure. ASHE-ERIC Higher Education Report (Vol. 30, No. 3). San Francisco: Jossey-Bass.

Cross, T. (2007). Black student college graduation rates inch higher but a large racial gap persists. The Journal of Blacks in Higher Education, (54). Retrieved from http://www.jbhe.com/preview/winter07preview.html

Davis, M., Dias-Bowie, Y., Greenberg, K., Klukken, G., Pollio, H. R., Thomas, S. P., \& Thompson, C. L. (2004). "A fly in the buttermilk": Descriptions of university life by successful black undergraduate students at a predominately White southeastern university. The Journal of Higher Education, 75(4), 420-445.

Johnson, N. Earnest, K., Huntley, H., Hensen, K., Reason, R., Saunders, K., \& Schuh, J. H. (Eds.). (2005). Editors' notes: Special issue: Addressing persistence and retention issues of historically underrepresented students. Journal of College Student Retention: Research, Theory \& Practice, 6(1), 1-2.

Jones, L., Castellanos, J., \& Cole, D. (2002). Examining the ethnic minority student experience at predominantly White institutions: A case study. Journal of Hispanic Higher Education, 1(1), 19-39.

Kobrak, P. (1992). Black student retention in predominantly White regional universities: The politics of faculty involvement. The Journal of Negro Education, $61(4), 509-530$.

Love, D. (2008). Revitalizing retention efforts for African-American college students at predominately White institutions. Proceedings of the Allied Academies International Conference, 15(2), 117-122.

Nagda, B. A., Gregerman, S. R., Jonides, J., von Hippel, W., \& Lerner, J. S. (1998). Undergraduate student-faculty research partnerships affect student retention. Review of Higher Education, 22(1), 55-72.

Patton, L. D., Morelon, C., Whitehead, D. M., \& Hossler, D. (2006). Campus-based retention initiatives: Does the emperor have clothes? New Directions for Institutional Research, 130, 9-24.

Provasnik, S., \& Shafer, L. L. Historically Black colleges and universities, 1976 to 2001 (NCES 2004-062). U.S. Department of Education, National Center for Education Statistics. Washington, D.C.: Government Printing Office.

Rodgers, K. A., \& Summers, J. J. (2008). African American students at predominantly White institutions: A motivational and self-systems approach to understanding retention. Educational Psychology Review, 20(2), 171-190. 
Sedlacek, W. E. (1999). Black students on White campuses: 20 years of research. Journal of College Student Development, 40(5), 538-550.

Solorzano, D., Ceja, M., \& Yosso, T. (2000). Critical race theory, racial microaggressions, and campus racial climate: The experiences of African American college students. The Journal of Negro Education, 69(1/2), 60-73.

Tierney, W. G. (1999). Models of minority college-going and retention: Cultural integrity versus cultural suicide. The Journal of Negro Education, 68(1), 80-91. 